\title{
Question Time: Questionnaires and Maastricht
}

\author{
Alasdair Blair \\ Final Draft Politics, Vol.19. No.2, 1999, pp.117-124, ISSN: 0263-3957.
}

\begin{abstract}
One of the most significant questions facing researchers engaged in contemporary history is the use of sources. These might include archival, oral, visual, electronic or printed sources. The particular mix employed will depend on the topic covered and the amount of time and money available to conduct the work. This article reviews both the importance and limitation of questionnaires for examining contemporary history in light of the advice provided in methodological texts.
\end{abstract}


Questionnaires are one of a variety of sources available to those engaged in contemporary political research (Brivati, 1996). Their advantage over others, particularly interviews, is the ability to supply information in an easy manner. They are, however, not without their problems. It is the objective of this article to examine why, when and how questionnaires are of help, by drawing upon my own research of the Maastricht Treaty. That work yielded a rich supply of sources, including private papers, parliamentary debates, speeches, draft negotiating texts, television and radio documentaries, books, journals and the press. Interviews were additionally conducted with those central to the negotiations, often providing otherwise unavailable information.

That the primary aim of interviews is to uncover specific information can aid other research strategies, such as survey questionnaires, and hence qualitative data can assist the process of quantitative evaluation (Seldon and Pappworth, 1982). The usage of questionnaires as a method of conducting social science research has been well demonstrated in recent political science literature (Nossiter, 1996, pp.326-341), including specific focus on the attitude of both the Conservative and Labour Party towards European integration (Baker et al 1994 and 1995; Norris, 1998). These professional studies have certain advantages over research undertaken by doctoral students who seek to collect their own data set. In the first instance, they tend to be conducted by trained researchers with prior experience of the design, execution and use of questionnaires. Second, they benefit from the financial backing of large research grants that permit more detailed surveys, including follow-up contact. These factors lend themselves towards a more authoritative survey in terms of scope, methodology and response rate. 


\section{A question of sources}

Texts dealing with research methods rarely mention what seems a crucial element of the research process, namely luck. No matter the extent to which research skills have been polished, it is luck that often ensures that findings are not limited. One senior civil servant was willing to conduct an interview because of location: being based at Leicester University found favour, as he was a native of the City. From such contacts it was possible to construct a wider web of interviews and correspondence. This type of strategy is often referred to as snowballing, whereby the researcher starts out with one or two individuals from the target group who they then ask to be put in contact with others. As a less scientific method it is useful for obtaining a sample from groups which are difficult to contact as a result of confidentiality, and who cannot be recruited in sufficient numbers through random methods of selection. Manuals such as the Civil Service List only provide limited information and do not detail those officials taking part in key Cabinet Committees, such as European Questions (Steering). The only way to obtain knowledge of those who participate in such groups is through a snowballing strategy, and is a crucial detail which some research methods texts overlook, although Devine highlights this issue (Devine, 1995, p. 142). Information obtained from one interview feeds future work by providing a basis from which new data can be collected. A particular benefit of this type of approach is its flexibility because ideas can be adapted in the process of collecting information and differs from the rigid approach of surveys, where assumptions are intertwined with the method of obtaining data. But a snowballing strategy only works when it is possible to gain access to the target population. In this context, obtaining interviews with MPs proved far more difficult, 
partly because the divisive nature of the negotiations meant many were unwilling to open weeping wounds. (A total number of six MPs were interviewed, representing $11 \%$ of the 52 interviewees).

There are, of course, many helpful guides to the mechanics of conducting interviews while Ph.D students are compelled to attend research methods courses (Seldon, 1988, pp.9-12; Devine, 1995, pp.137-153). But such information does not prepare researchers for the interview process. It is often unclear how a Ph.D student can extract information from politicians and officials who are, after all, adept at evading questions and manipulating interviews? While some research manuals propose that the interviewer should send questions to the prospective interviewee, I found this to occasionally be a disadvantage. A common thread that ran through rejection letters was that the list of names that I used as recommendations resulted in numerous individuals stressing that they would be unlikely to add to the views of those who I had interviewed. At a further level, the supplying of questions to those who provisionally accepted to conduct an interview resulted in subsequent letters of rejections.

As with most successful war campaigns, careful planning assists the interviewer. Pilot interviews clarify questions to be targeted at key individuals. The divisive nature of the Treaty negotiations ensured that the particular views of a Europhile or Eurosceptic Minister could be used when interviewing someone from an opposite spectrum. This proved especially useful in motivating individuals to challenge particular beliefs that could then be checked for accuracy in interviews with government officials who were often prepared to clarify events. 
How does one use this information? While May details the method and process of conducting interviews, little attention is given to how material should be sourced (May, 1997, pp.109-131). In my experience, this is the crucial point, especially as the majority of respondents were still employed by the government. It was therefore not surprising that the vast majority of those interviewed did not wish their views to be directly sourced. Although this does allow the interviewee to feel less constrained, a lack of attributable sources can lessen the value of the research. A method of increasing the number of attributable sources is to consult interviewees on the information to be sourced. But this can result in some comments being changed so as to meet the interviewees requirements. This presents a dilemma because the researcher has to determine whether it is wise to have an attributable or unattributable interview. As a general rule, the former is preferable but content should not be significantly altered for the sake of the latter.

\section{Questionnaires: why, when and how}

That the method of snowballing did not provide a similar level of success with MPs meant research findings would not take into account the views of all who had some involvement in the negotiations. One reason why MPs were less willing to be consulted was that the Maastricht Treaty, and particularly its ratification, became a contentious issue within the Conservative Party. This limited the number of individuals who were willing to be interviewed because they did not want to deepen divide within the Party. Second, those who were central to the negotiation of the Treaty were still in government, and many still in Cabinet. They were therefore unwilling or unable to assist. 
Third, many MPs either lost their seat or retired at the 1992 general election and were no longer able to be contacted. Thus, interviewing an information-rich target population was fraught with difficulties. In such a scenario, it is possible to use a survey as a means of conducting social research. This type of work involves the aim of providing numerical descriptions, such as 60 per cent of the population believe X (De Vaus, 1991).

The main benefit of a survey is that it enables issues to be compared and links between points established. It appeals to researchers as a method of collecting and analysing large amounts of information and provides a snapshot of the target audience. Here lies a difference between the benefit of an interview with an official or Cabinet Minister who helped construct policy and a backbench MP who was peripheral to the process. Time invested in an interview with the latter does not produce the same benefits as the former. A questionnaire was therefore beneficial in sampling the views of those peripheral to the research, or those unwilling or unable to be interviewed, but willing to respond to a questionnaire. It was equally helpful in ensuring that other tasks could be conducted while responses were being collated.

This is especially the case for surveys of MPs. There is no point in sending surveys during the annual recess of Parliament, while there is little validity in conducting work at crucial periods of the Parliamentary calendar. It is far better to conduct a survey when the majority of MPs are likely to be at Westminster and when their workload is not overburdened. The less pressure on the MP, the greater the likelihood of reply. As response rates differ, the research should preferably be conducted at a time when it is possible to conduct other tasks. Planning is vital because questionnaires involve both time and financial resources. The very construction of a questionnaire is a lengthy 
process, while overheads of printing, envelopes and postage (both outward and return) mean that it is important to get it right first time.

\section{Structure}

Having decided that a questionnaire is a suitable method of research, it is important to consider the target audience. Will a statistical random sample be used, or will a complete survey be the proffered alternative? If the former is chosen, it is essential to ensure that the target sample is representative of the audience as a whole. The benefit is that it is possible to construct a pattern of unbiased responses from a small sample, saving financial cost and reducing time pressures. The difficulty is that in the case of MPs, it is not necessarily possible to construct a representative sample (May, 1997, p.85). A random survey is only feasible when the researcher can be sure that the target audience is divided appropriately.

This proved difficult to achieve for research of the Maastricht Treaty. It was not feasible to divide MPs into categories, such as Eurosceptics or Europhiles. It was also not clear who would fit into specific groups; MPs who were vehemently Eurosceptic after the Danish referendum of May 1992 did not adopt such strong views in the course of the negotiations. In any case, Eurosceptic MPs tended to be divided on subject preferences, with Teddy Taylor favouring economic independence rather than European integration, while Bill Cash opposed the further loss of Westminster's legislative sovereignty. As the questionnaire would target specific preferences, a division on Europhile or Eurosceptic grounds would be likely to produce inaccurate responses. Equally, a sample of specific groups of MPs, such as backbenchers, Parliamentary 
Under-Secretaries of State, Ministers of State and Cabinet Ministers would be unlikely to provide a legitimate survey as it would be difficult to take into account Eurosceptic or Europhile views.

In this context a broad mail survey of 270 Conservative MPs and members of the government who sat in Parliament during the 1990-1991 session, including those members of the government who sat in the House of Lords, was deemed the proffered alternative. It was, however, not a complete sample of all Conservative MPs because some members had subsequently died, while it proved impossible to contact all of those who had not been re-elected or chose to retire at the 1992 general election. This meant responses were not totally representative.

This leads to a further point of whether a survey should be anonymous or not. If the latter option is chosen, then numbering questionnaires is a favourable means of ensuring who has responded and who has not. This has the further advantage of allowing followup questionnaires to those who have not responded, the intention being to drive up the overall response rate. In the case of this research, numbering was not perceived to be a suitable method as this may have compromised anonymity, while the limited funds available for the research did not permit follow-up work. Questionnaires were therefore divided between four groups: 21 Cabinet Ministers, 25 Ministers of State, 37 Parliamentary Under-Secretaries of State, and 187 Backbench MPs through the use of different coloured paper for each sample. This provided the opportunity to obtain information regarding the views of different sectors of the Conservative Party for comparative purposes. 
What ought to be included in the questionnaire? It should ideally be clear and easy to complete. Clarity is crucial for both the covering letter (so as to attract the initial attention of the target audience) and the structure of the questions (so as to keep the target audience focused and to ensure that full answers are provided). Complex questions should not be included, particularly if the target audience consists of individuals who do not have detailed subject knowledge. Questions ought not to be loaded with the purpose of obtaining a particular response (although a certain approach is built into the survey), but should invite answers from a broad selection of choices pertinent to the topic. It is additionally important to consider whether open or closed questions should be used. While the latter will limit the number of possible responses, it is easier to interpret. One possibility is to provide a mix, whereby respondents have the ability to list their own views if the alternative options are not acceptable. Open-ended questions are less suited to broad surveys encompassing large numbers of questionnaires. This is because the overall aim of a survey is to produce a structured set of data which can be easily interpreted, of which a number of statistical packages have been specifically designed for use by social scientists, particularly Statistical Package for the Social Sciences. A further point is that any preliminary work, such as archival or interview research, will obviously influence the questionnaire design as the researcher acquires knowledge of primary concerns. This will also influence the order of the questions as it is important to develop a rhythm for the survey. Complex or difficult questions should be interspersed with those of an easier, or YES/NO nature to make the questionnaire as user-friendly as possible. But this is a further point often overlooked in the research literature. 


\section{Value}

The data I obtained from the survey consisted of 72 completed questionnaires, providing a further source of information on the Maastricht Treaty negotiations. But they were not used as the cornerstone of the research. First, it was considered questionnaire responses would not provide a sufficiently accurate account of the negotiations, as they did not represent a proportional random sample. The understanding from the outset was that questionnaires would only provide a means of either contradicting or reiterating evidence obtained from sources such as interviews. Second, as no attempt was made to number the questionnaires, it was possible that an imbalance was obtained from certain groupings of the Conservative Party, such as Eurosceptics.

The data did, however, demonstrate general concerns among the individual groupings and further enriched the overall research. The four categories of backbench MPs, Parliamentary Under-Secretaries of State, Ministers of State and Cabinet Ministers were then grouped to form a cumulative response. The benefit of this strategy was that it allowed comparisons to be made between specific groups and the average, but it had the additional problem of imparting an element of distortion. For instance, the introduction of qualified majority voting for foreign policy was only considered by $5 \%$ of MPs (cumulative response) to be the most damaging issue, with that view only held by backbench MPs. By contrast, $52 \%$ of respondents considered the inclusion of a federal goal to be the most damaging of all the issues during the IGC (see appendix 1, question 6). This priority was represented in among all respondents. Yet, the reality was that the federal goal was not an important negotiating point, while foreign policy was. 
A difference between backbench MPs and other groupings was crucial to highlighting the extent to which MPs were kept in the dark over government negotiating strategies. This was a view I had obtained in interviews and was further emphasised by the lack of comments concerning the co-decision procedure during the June 1991 Parliamentary debate on the draft negotiating text. The inclusion of the federal goal in preliminary treaty drafts ensured that the attention of the media and MPs were excessively focused on that issue. When it became apparent that the word 'federal' had been taken out of the Treaty by early December 1991, UK politicians perceived this to be a great success. Acceptance of difficult points, including the granting of co-decision powers to the European Parliament, were deemed more palatable by backbench opinion.

\section{Conclusion}

Questionnaires are in consequence an important source of information for the research process. They help to enrich investigative work and add credence to views that may otherwise be unsubstantiated. But the various methodological problems that surround both the nature of questionnaire design and the utilisation of results can constrain the effectiveness of the process. This was a difficulty I encountered. A means of alleviating this was to reduce the 'weight' given to the responses obtained in the attached questionnaire. That, however, is not to downgrade the importance of such a method, it is merely a call for greater clarity in the provision of research training. 
Appendix 1: Cumulative response of questionnaire (270 sent, 72 replied)

1. Rank in order of importance the factors you think were influential in Mrs Thatcher's downfall as Prime Minister.

First choice $(n=72, \%=27)$

a) Fear of losing the next General Election

b) Domestic disputes such as the Community Charge

c) Dissent within the Parliamentary Party

d) Splits within Cabinet due to dominant style of government

e) Lack of a constructive position in Europe

f) Other: Cabinet changes
Number $\%$

$21 \quad 40$

$19 \quad 26$

$11 \quad 15$

$8 \quad 1$

46

12

2. Do you think there has been greater or less consensus within Cabinet under John Major's premiership than under Margaret Thatcher's, and has that resulted in more or less effective decision making?

$2.1(n=64, \%=24)$

a) Greater consensus

b) Less consensus

c) Other: neither

$2.2(n=59, \%=22)$

a) More effective

b) Less effective
Number $\%$

$45 \quad 70$

$15 \quad 24$

$4 \quad 6$ 
c) Other: no change 
3. Do you think that the UK was more or less constructive in its role in the European Community (Union) under John Major's premiership in 1990-1991 than under that of Margaret Thatcher? $(n=66, \%=24)$

\section{Number \%}
a) More constructive
$41 \quad 66$
b) Less constructive
124
c) Other: less influential, little difference.
$9 \quad 14$

4. Do you think backbench MPs were consulted more under John Major's premiership in 1990-91 than under Margaret Thatcher? $(n=68, \%=25)$

\section{Number \%}
a) More consultation
$49 \quad 72$
b) Less consultation
$5 \quad 7$
c) Other: equally the same, no difference
$14 \quad 21$

5. Do you think a close relationship between John Major and Helmut Kohl was crucial to the UK obtaining the opt-outs on EMU and social policy at the Maastricht European Council in December 1991? $(n=66, \%=24)$

\section{Number \%}
a) Crucial
$37 \quad 56$
b) Not crucial
$23 \quad 35$
c) Other: opt-outs are total sham, don't know, of some help.
69 
6. Of the following issues could you rank in order of importance which you considered most damaging to the UK?

First choice $(n=66, \%=24)$

Number $\%$
a) Federal goal
$33 \quad 52$
b) Single currency
$12 \quad 19$
c) Social Chapter
$8 \quad 13$
d) Stronger powers for the European Commission
$5 \quad 8$
e) Majority voting for Foreign Policy 3
f) Co-decision $\quad \begin{array}{ll}1 & 1\end{array}$
g) Stronger powers for the European Parliament $\quad 1 \quad 2$
h) Other 111

7. Of the following issues could you rank in order of importance which you considered most important to be obtained at the Maastricht European Council?

7.1 First choice $(n=63, \%=23)$

Number $\%$

a) Deletion of commitment to a federal goal

$18 \quad 28$

b) Non-binding commitment to 3rd stage of EMU

$15 \quad 24$

c) Commitment to subsidiarity

$12 \quad 19$

d) Social Chapter opt-out

$12 \quad 19$

e) Retention of existing institutional balance

35

f) Pillar Treaty structure

35


g) No incorporation of WEU into EU 
8. Do you think that the Maastricht European Council was a negotiating success for the UK? $(n=65, \%=24)$

$$
\text { Number } \%
$$
a) Yes
$43 \quad 66$
b) No
$22 \quad 34$

9. Was the position adopted by the government at Maastricht influenced by backbench MPs? $(n=69, \%=26 \%)$

\section{Number \%}
a) Yes
$51 \quad 74$
b) No
S17 25
c) Other: a bit
1

\section{Acknowedgement}

The author would like to express his thanks to Robert Garner, Philip Lynch and John Young of the Politics Department at Leicester University and two anonymous referees. 


\section{References}

Baker, D. et al (1994) 'What Tory MPs think about Europe', Parliamentary Brief, Vol. 3, No. 3, December.

Baker, D. et al (1995) 'The Blue Map of Europe: Conservative Parliamentarians and European Integration' in British Elections and Parties Yearbook, London: Frank Cass.

Brivati, B. et al (eds.) (1996) The Contemporary History Handbook, Manchester: Manchester University Press.

De Vaus, D. (1991) Surveys in Social Science Research, London: UCL Press.

Devine, F. (1995) 'Qualitative Analysis' in D. Marsh and G. Stoker (eds.) Theory and Methods in Political Science, Houndmills: Macmillan.

May, T. (1997) Social Research, Buckingham: Open University Press.

Norris, P. (1998) 'New Labour, New Politicians?', Contemporary Political Studies, Vol.2, pp.766-779.

Nossiter, T. (1996) 'Survey and Opinion Polls' in B. Brivati, et al (eds.) The Contemporary History Handbook, Manchester: Manchester University Press, pp.326-341.

Seldon, A. and Pappworth, J. (1982) By Word of Mouth, London: Methuen.

Seldon, A. (1988) 'Interviews' in A. Seldon (ed.) Contemporary History: Practice and Method, Oxford: Basil Blackwell. 